\title{
Classification of femoral neck fractures according to pauwels: interpretation and confusion — Reinterpretation: a simplified classification based on mechanical considerations
}

\author{
Andrej Maria Nowakowski ${ }^{1}$, Peter Emil Ochsner ${ }^{2}$, Martin Majewski ${ }^{1}$
}

${ }^{1}$ Orthopedic Department, University of Basel, Basel, Switzerland;

${ }^{2}$ Clinic for Orthopedics Lucerne, Klinik St. Anna, Luzern, Switzerland.

Email: andrej.nowakowski@unibas.ch

Received 29 March 2010; revised 3 May 2010; accepted 9 May 2010.

\begin{abstract}
The Pauwels Classification of femoral neck fractures, initially published in 1935, is used world-wide. Unfortunately, modern textbooks give varying angle and anatomic specifications between the classified fracture grades. This inconsistency is perpetuated in the literature, so that it is difficult to compare conclusions made by different authors. Pauwels himself left room for interpretation. He published two studies, one in 1935 and one in 1973, each including 3 diagrams. The 1935 version cited an angle of $8^{\circ}$ representing the vector of static forces acting on the femoral head. The 1973 diagrams, however, cited an angle of $16^{\circ}$ to represent dynamic forces, without changing the angle from horizontal. This already complex scheme is complicated by the fact that it depends on other factors such as femoral neck shaft (CCD) angle, femoral neck and head diameter, and/or distance of the fracture from the center of the femoral head. The multitude of factors argues against a rigid classification based on fixed angles from horizontal. Pauwels himself did not establish fixed critical angles between the fracture grades. In his own explanation of the system, he placed more value on mechanical considerations such as compression stress, shear stress, tensile force, shearing force, and torque. We propose therefore a simplified version of the Pauwels Classification: Grade I for fractures impacted in valgus, Grade II for fractures without free torque, and Grade III for fractures with free torque.
\end{abstract}

Keywords: Pauwels; Garden; Classification; Femoral Neck Fracture

\section{INTRODUCTION}

There is a pervasive wish for a simple classification system corresponding to the treatment of femoral neck fractures. One frequently used classification is that of Pauwels, originally published in 1935 [1]. Unfortunately, modern textbooks give varying angles and anatomic specifications to differentiate the three fracture grades. These inconsistencies are perpetuated in the scientific literature, so that it is difficult to make a clear correlation between fracture type, treatment modality and course of healing (Table 1 ).

The ambiguity of this system has doubtless contributed to the lack of consensus regarding its use. However, the classification per se is not at fault, instead, its interpretation. For example, some authors ignore entire segments $\left(50^{\circ}\right.$ to $\left.70^{\circ}\right)$ of injury in their interpretations. In addition, there are numerous publications that make comparison impossible, since they do not indicate which interpretation of the classification they are using [2-7].

Bartoniček [8] remarked on this problem in 2001 in his study, "Pauwels' Classification of Femoral Neck Fractures: Correct Interpretation of the Original," and stipulated the following categories:

Grade I $<30^{\circ}$, Grade II $30-50^{\circ}$, and Grade III $>50^{\circ}$.

However, Pauwels considers the fracture in his Figure 40 (page 39), to be a Grade I injury despite an angle of $35^{\circ}$. This, he explains, is because impaction negates the shearing forces [1]. (Figure 1).

Redefining the distinction between Grade I and II fractures as $35^{\circ}$ instead of $30^{\circ}$ is counterproductive. Instead, the original intent of Pauwels should be respected. This was to classify these fractures based on mechanical considerations.

\section{MATERIAL AND METHODS}

We examined the classification of femoral neck fractures based on pre-determined angles, using the two original publications from Pauwels [1,9]. In addition, theoretic considerations and modifiable variables were compiled 
Table 1. Diverse interpretations of the pauwels classification.

\begin{tabular}{cccc}
\hline Grade I & Grade II & Grade III & Literature \\
\hline$<30^{\circ}$ & $30-50^{\circ}$ & $>50^{\circ}$ & {$[80,10,14,19,21,22]$} \\
$<30^{\circ}$ & $30-60^{\circ}$ & $>60^{\circ}$ & {$[23]$} \\
$<30^{\circ}$ & $30-70^{\circ}$ & $>70^{\circ}$ & {$[13,20,24,25]$} \\
$30^{\circ}$ & $50^{\circ}$ & $70^{\circ}$ & {$[12,26,27]$} \\
$<50^{\circ}$ & $50-65^{\circ}$ & $>65^{\circ}$ & {$[28]$} \\
$<30^{\circ}$ & $30-50^{\circ}$ & $>70^{\circ}$ & {$[29]$} \\
\hline
\end{tabular}

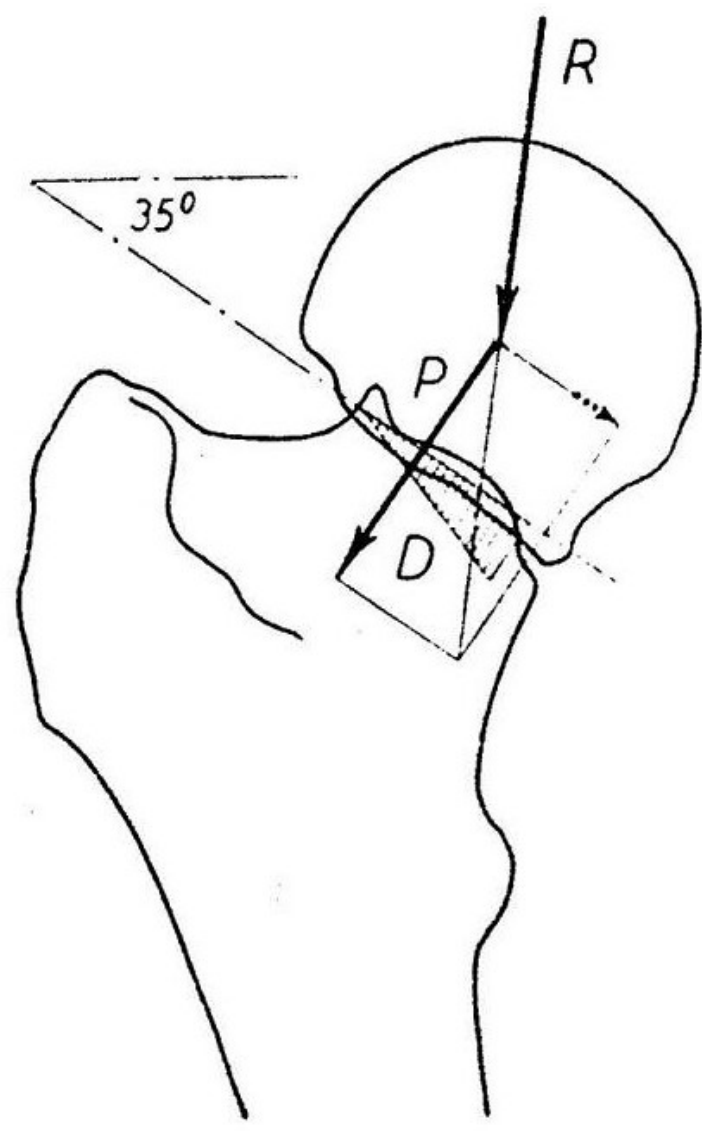

Figure 1. Original illustration by Pauwels 1935 [1] showing a fracture impacted in valgus without free shearing force (Grade I). Reprinted by courtesy of Georg Thieme Verlag KG, Stuttgart, after transfer of Ferdinand Enke Verlag, Stuttgart, from 1971.

and incorporated into a simplified version of the Pauwels' Classification.

\section{RESULTS}

The most important criteria for the Pauwels Classification are found in the legend describing his Figure 2 [1].

Grade I: The partial compressive force component $\mathrm{P}$ acts only as its magnitude approaches the value of R. The partial force of pure displacement $\mathrm{S}$ is countered by friction at the fracture site. $\mathrm{P}$ generates compression forces distributed evenly over the entire fracture surface, because $\mathrm{R}$ intersects the fracture surface adjacent to the mid-line.

Grade II: Here the free shearing force Ks will act on the zone of fracture healing. The compression component $P$ will not act on this area, instead will generate latent compressive forces in only one portion of the fracture surface.

Grade III: The free shearing force $\mathrm{Ks}$ and tensile force $\mathrm{Z}$ are generated by free torque (R, OA).

Only the lowest corner of the trochanter fragment (O), the fulcrum for the head fragment, will be acted upon by latent compressive forces.

Differentiation between Grade I and Grade II fractures, then, is made based on the presence or absence of the free shearing force Ks. When shearing force is present, the fracture is a Grade II. This explains why some fractures impacted in valgus, despite steep fracture angles, are considered Grade I fractures. Impaction neutralizes Ks. (Figure 1) According to Pauwels [1]: "Under certain circumstances, impaction may have a decided influence on the course of healing, because it neutralizes a certain measure of the displacement force $\mathrm{S}$ and therefore reduces the extent to which the free shearing force Ks acts on the zone of fracture healing." In cases of more vertical fractures, however, the compression achieved from impaction can no longer neutralize the dynamic shearing forces [1].

The differentiation between Grade II and III fractures is made based on the free torque (R, OA). When free torque is present, the fracture is Grade III.

Interestingly, almost 40 years after the initial paper, Pauwels published modified diagrams [9]. These stipulate a dynamic force vector $\mathrm{R}$ with an angle of $16^{\circ}$ instead of the static vector of $8^{\circ}$ found in the original version. (Figure 3)

It is possible that improved operative techniques and implant devices allowing partial weight bearing and early mobilization of the patient led to this alteration.

Pauwels wrote even in 1935 [1] that Grade II fractures are those with a fracture inclination up to $50^{\circ}$. His own diagram shows a fracture with a distinctly steeper fracture angle than $50^{\circ}$, however, without free torque. (Figure 3(c)) Manipulation of the vector angles alone, dependent on other factors, can blur the distinction between categories, i.e., the values of the angles of inclination.

Figure 4 demonstrates this for the border between Grade II and III fractures. (Figure 4)

The location of the fracture along the femoral neck medially or laterally has a definite influence on the presence or absence of free torque. (Figure 5)

Other factors influencing the critical angles are: the femoral neck shaft (CCD) angle, the femoral neck and head diameters, and/or distance from the fracture to the 

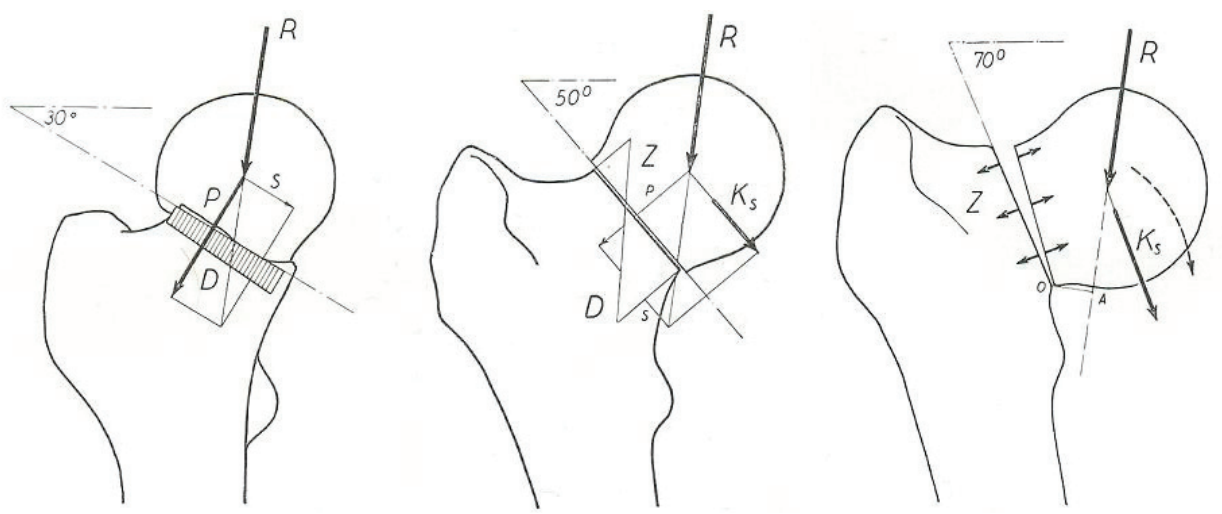

Figure 2. Original illustration by Pauwels 1935 [1]: Classification of femoral neck fractures. Reprinted by courtesy of Georg Thieme Verlag KG, Stuttgart, after transfer of Ferdinand Enke Verlag, Stuttgart, from 1971.

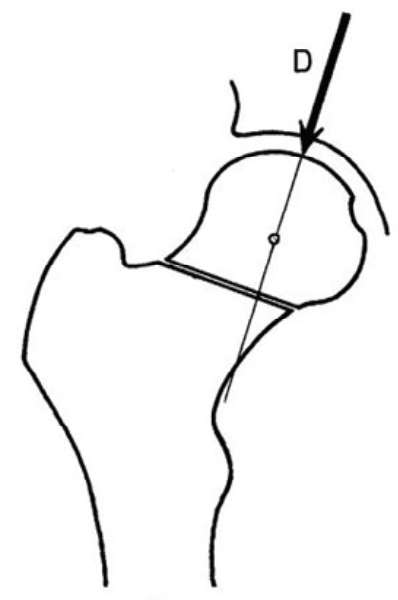

a

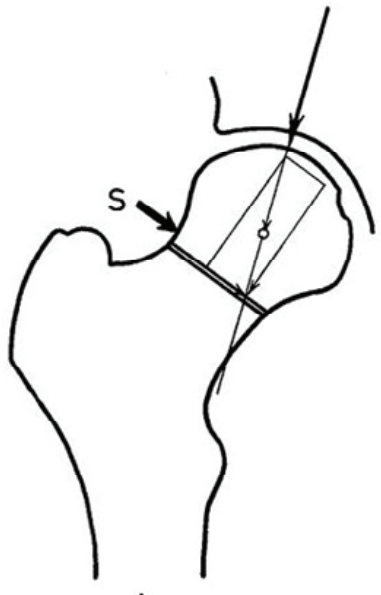

b

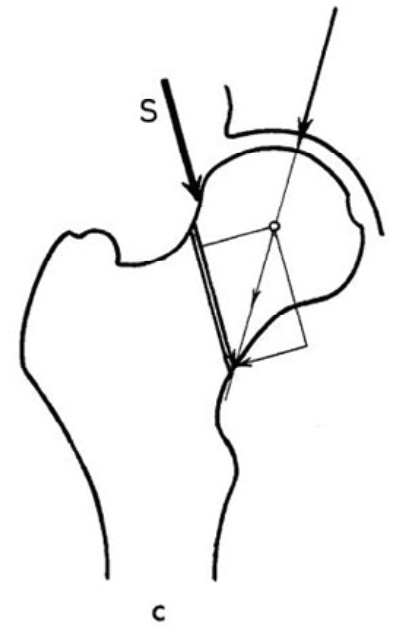

c

Figure 3. Original illustration by Pauwels 1973 [9]: Classification of femoral neck fractures. Reprinted by courtesy of Springer-Verlag Berlin/Heidelberg.

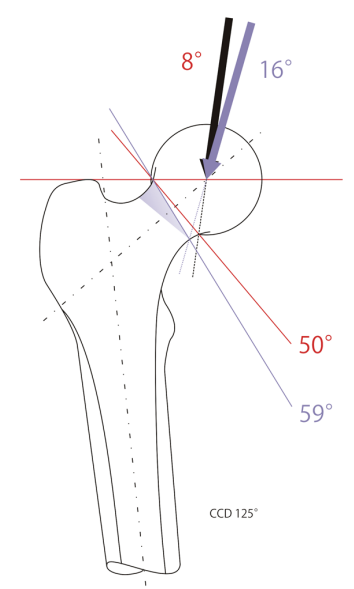

Figure 4. Impact of different vectors on the classification of femoral neck fractures. Relationship demonstrated for the border between Grade II and III fractures. center of the femoral head. For example, then, fractures in varus hips will reach a higher fracture grade when the angles are smaller than those of fractures in valgus hips. (Figure 6)

These issues clearly demonstrate that a rigid classification system using defined angle measurements is not practical. The Pauwels study [1] assigns fractures in valgus an exceptional position. We propose, therefore, a simplified version of Pauwels' Classification, based on mechanical considerations:

Grade I: fractures impacted in valgus,

Grade II: fractures without free torque,

Grade III: fractures with free torque.

\section{DISCUSSION}

Parker and Dynan [10] declared the Pauwels Classification clinically irrelevant due to the multitude of studies 

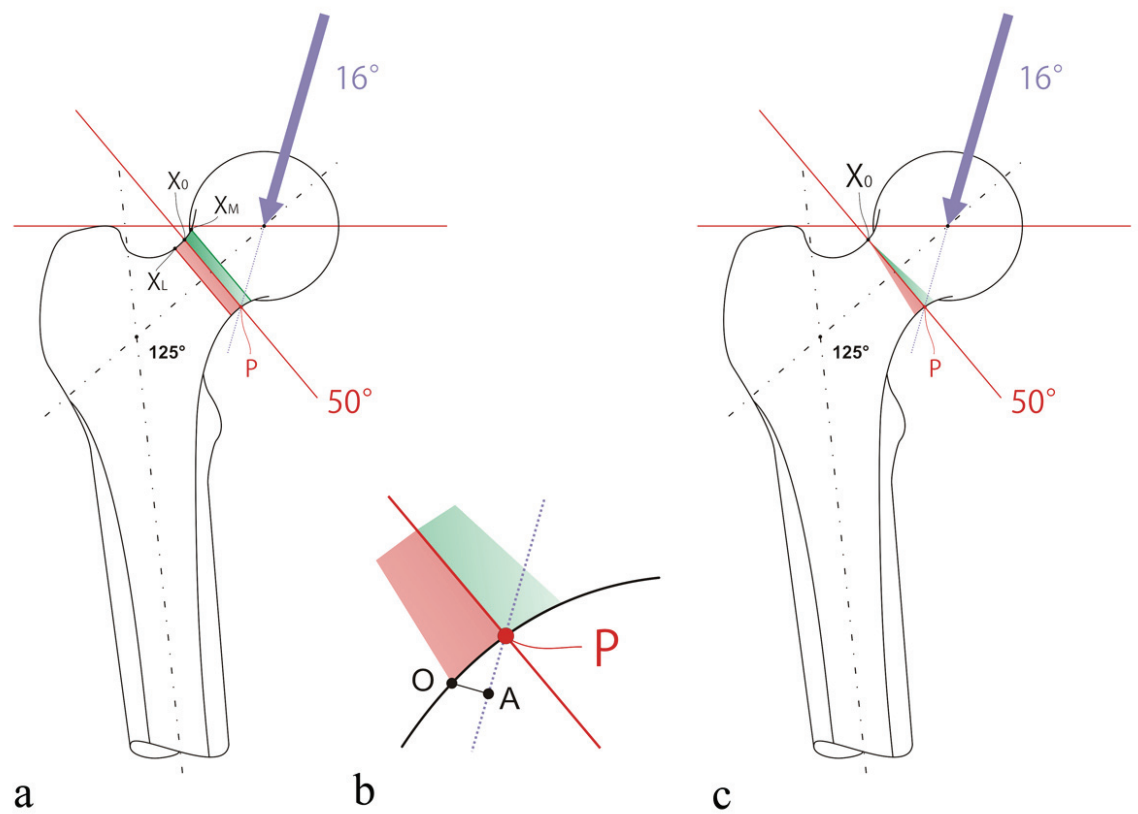

Figure 5. Demonstration of boundary zone for femoral neck fractures Grades II and III at a theoretical fracture starting point $\mathrm{X}_{0}$ and a fracture angle of $50^{\circ}$ to horizontal; (a) More lateral fractures $\left(\mathrm{X}_{\mathrm{L}}\right)$ lead to the presence of free torque, more medial fractures $\left(\mathrm{X}_{\mathrm{M}}\right)$ do not. (b) Magnification of (a) and (c): more lateral fractures or more vertical fracture angles at critical point $\mathrm{P}$ lead to the presence of free torque (R, OA). (c) More vertical angles (red zone) lead to the presence of free torque, more horizontal fractures (green zone) do not.

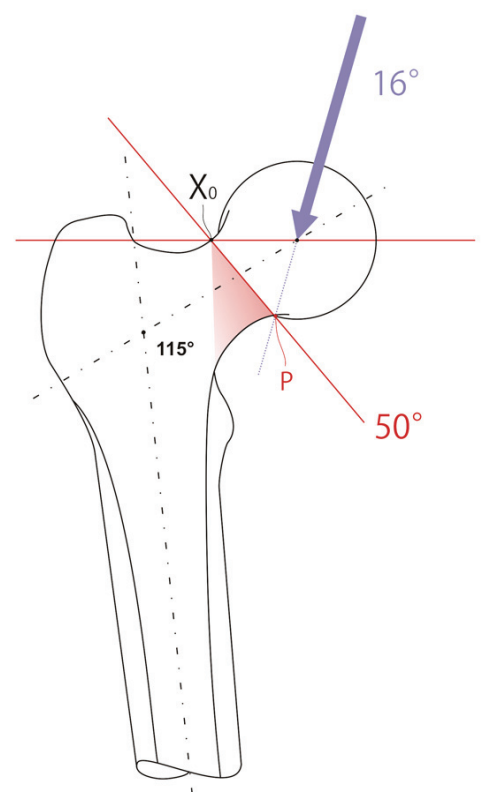

a

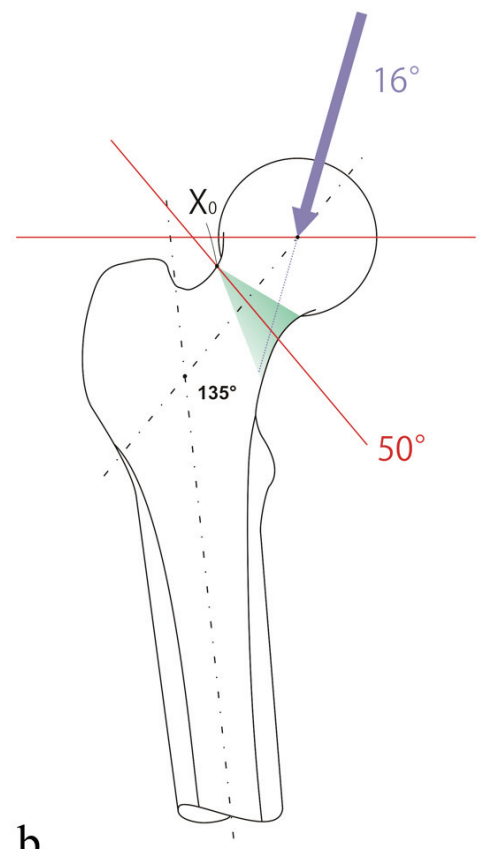

b

Figure 6. Influence of the CCD-angle on boundary zones for the Pauwels Classification 1973 [9], demonstration of Grades II and III, starting at a theoretical fracture point $\mathrm{X}_{0}$ : (a) More varus $C C D$-angles lead to the presence of free torque $(R, O A)$ at critical point $P$ in many cases. (b) More valgus CCD-angles seldom lead to the presence of free torque (R, OA). 
showing no correlation between Pauwels' angles and non-union. This statement is based most notably on two large studies, from Otremski, et al. [3] and Raaymakers and Marti [11], which showed no correlation between fracture angle and secondary displacement and/or nonunion in impacted femoral neck fractures. Verheyen et al. [12] determined that the critical angle between Grade I and Grade II injuries is impractical, since almost all cases of impacted femoral neck fractures lie in the gray area and it is too difficult to differentiate them.

However, in his original 1935 work, Pauwels [1] emphasized the exceptional nature of impacted femoral neck fractures (Figure 1).

The conclusions from individual studies are difficult to compare, but this is due to varying interpretations of the critical angles. The problem does not lie with the Classification itself. For instance, Krastman, et al. [13] established a Pauwels Grade II as $30^{\circ}$ to $70^{\circ}$, and allocated $71 \%$ of 112 cases as Grade II injuries. In contrast, Prinčič, et al. [5] identified only $7.1 \%$ of 351 cases as Pauwels Grade II injuries. They did not indicate which critical angles they used.

The Pauwels Classification has also been criticized regarding the difficulty to determine angles preoperatively because of rotational error [3,11]. Projection errors are a generalized problem for fracture evaluation, however, and are ubiquitous in all two-dimensionally imaged fractures that are not taken orthograde. Graphic techniques, i.e., comparison of the contralateral side, can be of assistance. As well, intraoperative radiographs postreposition, as suggested by Raaymakers $[14,15]$ can be used to combat this problem.

Another criticism of femoral neck fracture classifications is that they don't consider the second plane. This is true of the Pauwels Classification [1], which doesn't use the lateral plane, as well as the Garden Classification [16], for which in clinical practice it is often neglected. Because of this, and because of variability in interpretations, Frandsen, et al. [17] and Zlowodszki, et al. [18] suggested that the Garden Classification [16] is no longer useful in clinical practice.

Individual studies have identified correlations between fracture angle and the occurrence of secondary displaycement and/or non-union [4-6]. Many authors use the Pauwels [1] as well as the Garden [16] Classifications to evaluate the respective risks of non-union or femoral head necrosis and to determine the best mode of treatment $[2,7,13,19,20]$.

On the one hand, there is the need to predict post-operative course based on measurable pre-operative parameters, and to thereby choose the best method of treatment. On the other hand, these parameters should not be too complicated for regular clinical use, since that can lead to confusion and sub-optimal therapeutic choices. Therefore, the newer classification developed by $\mathrm{Ca}$ viglia, et al. [21], with its six grades of fracture and ten subdivisions, appears too complex for routine clinical use in evaluating femoral neck fractures. The inclination of the fracture continues to be an important consideration to estimate the course of healing and determine the best method of treatment. Fractures impacted in valgus remain a special category. Although in these cases more vertical fractures can be more mechanically favorable, it is important to pay close attention for the presence of dorsal tilting.

At the time of Pauwels' writing, it was important to distinguish non-impacted femoral neck fractures having a moderate fracture angle but no free torque, since this influenced the choice of therapy. However, simple nailing procedures are no longer performed. Instead, more reliable techniques such as minimally-invasive fixation with two to three gliding or pressure screws or larger implants such as a dynamic hip screw (DHS) are used. We believe that the indications for internal fixation versus hemi-arthroplasty should be based not only on the risk of femoral head necrosis (i.e., using the Garden Classification), but also on the mechanical constellation of injury. This is generally accepted for the treatment of femoral neck non-unions. In the area of femoral neck fractures, however, no classifications using pure mechanical analysis can be implemented, either because they are too complex, or because they have not been comparably interpreted by the literature.

For all of these reasons, we propose the following simplified version of the Pauwels Classification system for femoral neck fractures based on mechanical considerations. Grade I fractures are those impacted in valgus, Grade II are fractures without free torque, and Grade III are fractures with free torque. To differentiate between Grade II and III fractures, the dynamic resulting vector $\mathrm{R}$ $\left(16^{\circ}\right)$ should be projected from the center of the femoral head onto the level of fracture. If the vector intersects the fracture surface, the injury is a more mechanically favorable Grade II injury without free torque. If, however, the vector projection intersects medial to the fracture plane, free torque is present and the injury is an unfavorable Grade III type, with increased risks of secondary displacement, femoral head necrosis, and/or nonunion.

This extrapolation, strictly interpreted, is a simplification of a complex mechanical relationship. The angle of incidence of the resulting vector $\mathrm{R}$ is dependent on the leverage variables (CCD angle, femoral neck length, etc.) and multidimensional. However, overall it is better defined and more reproducible as a measure of the presence of free torque than the fracture angle from horizontal. 
This classification can be used for borderline cases, definitively, in the operating room. Moreover, an enhancement of the mechanical constellation can be obtained using valgisation of the fracture.

Whether this modified classification is sufficient to predict the development of mal/non-union and/or femoral head necrosis, and therefore the need for fixation versus hemi-arthroplasty, remains to be seen. Further studies will be necessary to evaluate its use in the clinical setting.

\section{REFERENCES}

[1] Pauwels, F. (1935) Der schenkelhalsbruch ein mechanisches problem. Z Orthop Ihre Grenzgeb, 63, 1-135.

[2] Angly, B. and Ochsner, P.E. (2004) Sind Gleitsc- hrauben bei medialen Schenkelhalsfrakturen älterer Men-schen eine taugliche Alternative zu Kopfprot-hesen? Akt Taumatol, 34, 123-127.

[3] Otremski, I., Katz, A., Dekel, S., Salama, R. and Newman R.J. (1990) Natural history of impacted subcapital femoral fractures and its relevance to treatment options. Injury, 21(6), 379-381.

[4] Penschuk, C., Zilch, H. and Brenner, M. (1982) Langzeitergebnisse der druckosteosynthese mit drei ao-spongiosaschrauben bei schenkelhalsfrakturen. Unfallchirurgie, 8, 33-40.

[5] Princic, J., Zupancic, F. and Cimerman, M. (1993) Late results of 351 femoral neck fractures (1986-1987 treatment period). Unfallchirurg, 96(9), 468-472.

[6] Roth, W. (1988) Complications following osteosynthesis management of femoral neck fractures with spongiosa locking screws. Aktuelle Traumatol, 18(1), 21-32.

[7] Scharf, W., Wagner, M. and Trojan, E. (1985) Differentiated procedure in fractures of the coxal femur end in adults. Aktuelle Traumatol, 15(5), 10-16.

[8] Bartonicek, J. (2001) Pauwels' classification of femoral neck fractures: Correct interpretation of the original. Journal of Orthopaedic Trauma, 15(5), 358-360.

[9] Pauwels, F. (1973) Atlas zur Biomechanik der gesunden und kranken Hüfte. Heidelberg, Berlin, Springer, New York.

[10] Parker M.J. and Dynan, Y. (1998) Is pauwels classification still valid? Injury, 29(7), 521-523.

[11] Raaymakers, E.L.F.B. and Marti, R.K. (1991) Non-operative treatment of impacted femoral neck fractures. A prospective study of 170 cases. Journal of Bone \& Joint Surgery $(\mathrm{Br}), \mathbf{7 3 ( 6 )}, 950-954$

[12] Verheyen, C.C.P.M., Smulders, T. C. and van Walsum, A. D. (2005) High secondary displacement rate in the conservative treatment of impacted femoral neck fractures in 105 patients. Arch Orthop Trauma Surg, 125, 166-168.

[13] Krastman, P., van den Bent, R. P., Krijnen, P. and Schipper, I. B. (2006) Two cannulated hip screws for femoral neck fractures: treatment of choice or asking for trouble?
Arch Orthop Trauma Surg, 126(5), 297-303.

[14] Raaymakers, E.L.F.B. (2006) Fractures of the femoral neck: A review and personal statement. Acta Chir Orthop Traumatol Cech, 73(1), 45-59.

[15] Raaymakers, E.L.F.B. and Schafroth, M. (2002) Medial femoral neck fracture. Controversies in treatment. Unfallchirurg, 105(2), 178-186.

[16] Garden, R.S. (1961) Low-angle fixation in fractures of the femoral neck. Journal of Bone \& Joint Surgery $(B r)$, 43, 647-663.

[17] Frandsen, P.A., Andersen, E., Madsen, F. and Skjodt, T. (1988) Garden's classification of femoral neck fractures. An assessment of inter-observer variation. Journal of Bone \& Joint Surgery $(\mathrm{Br}), \mathbf{7 0}, 588-590$.

[18] Zlowodzki, M., Bhandari, M., Keel, M., Hanson, B. P. and Schemitsch, E. (2005) Perception of Garden's classification for femoral neck fractures: An international survey of 298 orthopaedic trauma surgeons. Arch Orthop Trauma Surg, 125(7), 503-505.

[19] Füchtmeier, B., Hente, R. Maghsudi, M. and Nerlich, M. (2001) Repositioning femoral neck fracture in younger patients, valgus or anatomic reposition? Unfallchirurg, 104(11), 1055-1060

[20] van Meeteren, M.C., de Vries, L.S., Hammacher, E.R. and van der Werken, C. (1996) Reasonably good results of Hansson's pins in elderly patients with a medial femoral neck fracture. Ned Tijdschr Geneeskd, 140, 1552-1557.

[21] Caviglia, H.A., Osorio, P.Q. and Comando, D. (2002) Classification and diagnosis of intracapsular fractures of the proximal femur. Clinical Orthopaedics and Related Research, 399, 17-27.

[22] Gerber, P. and Wicki, O. (1995) Stadien und Einteilungen in der Medizin. Stuttgart, Thieme Verlag, New York.

[23] Bout, C.A., Cannegieter, D.M. and Juttmann, J.W. (1997) Percutaneous cannulated screw fixation of femoral neck fractures: The three point principle. Injury, 28(2), 135139.

[24] Bray, T. J. (1997) Femoral neck fracture fixation, Clinical decision making. Clinical Orthopaedics and Related Research, 339, 20-31.

[25] Krämer, K.L., Stock, M. and Winter, M. (1997) Klinikleitfaden Orthopädie. 2th Edition, Gustav Fischer Verlag, Stuttgart.

[26] Blauvelt, T.C. and Nelson, F.R.T. (1998) A manual of orthopaedic terminology. 6th Edition, C.V. Mosby Company, St. Louis.

[27] Hasse, F.M. and Müller, L.P. (2002) Klinikleitfaden Chirurgie. 3th Edition, Urban und Fischer Verlag, München.

[28] Brown, J.T. and Abrami, G. (1964) Transcervical femoral fracture: A review of 195 patients treated by sliding nailplate fixation. Journal of Bone \& Joint Surgery $(B r), \mathbf{4 6}$ 648-663.

[29] Kuner, K. and Schlosser, V. (1995) Traumatologie, 5th Edition, Thieme Verlag, Stuttgart, New York. 